\title{
Anesthetic management of a patient with hereditary angioedema: a case report
}

\author{
C. G. Lopes ${ }^{1}$, S. L. F. Cavalcante ${ }^{2}$, F. B. Lima², N. K. P. Fontenele ${ }^{2}$, J. C. R. \\ Nascimento $^{2}$, M. B. C. Fernandes ${ }^{2}$
}

1-Hospital São Carlos- Fortaleza (Brazil), 2-HGF-Hospital Geral de Fortaleza (Brazil)

\section{Background:}

Hereditary angioedema $(\mathrm{HA})$ is a rare and potentially fatal dominant autosomal disorder characterized by abnormal levels, or malfunctioning, of the inhibitor of the first component of the complement cascade (C1INH). Carriers experience recurrent episodes of edema involving the skin, mucosas, airway and gastrointestinal system. When an episode occurs perioperatively, the patient may present breathing difficulties and hemodynamic instability, requiring specific interventions to minimize morbidity. In this paper, we describe the anesthetic management of a patient with HAE.

\section{Case report:}

A female patient (32 years; $82 \mathrm{~kg}$ ) recently diagnosed with HAE was submitted to multiple tooth extractions. The condition was treated with danazol (100 mg.day) and tranexamic acid (500 mg.day), and the patient's overall condition was good: functional capacity $>4$ METS, quantitative C1-INH: 0.0514 g.L-1 (normal range: $0.21-0.39 \mathrm{~g} \cdot \mathrm{L}^{-1}$ ), otherwise normal physical and laboratory findings. On the morning of the procedure, frozen fresh plasma $(750 \mathrm{~mL})$ and tranexamic acid $(250 \mathrm{mg})$ were administered. Monitoring included $\mathrm{SpO}_{2}$, cardioscopy, NIBP and $\mathrm{BIS}$, and icatibant (a bradykinin receptor 2 antagonist) was available in the OR. Anesthesia was induced with sufentanil $(40 \mathrm{mg})$, lidocaine $(100 \mathrm{mg})$, propofol (100 $\mathrm{mg}$ ) and cisatracurium (8 mg), followed by nasotracheal intubation. The anesthetic depth (BIS 40-60) was maintained with sevoflurane and remifentanil TCl. At this point, the patient was given dexametasone (10 $\mathrm{mg}$ ) and tranexamic acid $(500 \mathrm{mg})$. No edema, hemodynamic or respiratory events occurred during or after the procedure. Following extubation, the patient was transferred to the recovery room and discharged 24 hours later.

\section{Discussion:}

Perioperative management of patients with HA should include prophylaxis, efficient monitoring and the availability of drugs to control crises. Evidence-based medicine suggests that the event may not respond to treatment with adrenaline or antihistamines, more specific therapy is needed. In the present case, prophylaxis was successfully achieved with frozen fresh plasma, antifibrinolytics and attenuated androgen (danazol), which are known to reduce the risk of a crisis during surgery. The airway was guaranteed and icantibant was available if needed to control severe respiratory distress.

\section{Reference:}

Vilaça MJL, Coelho FM, Faísco A et al. Considerações anestésicas perante um doente com angioedema hereditário - Caso clínico. Rev Bras Anestesiol, 2017;67:541-543

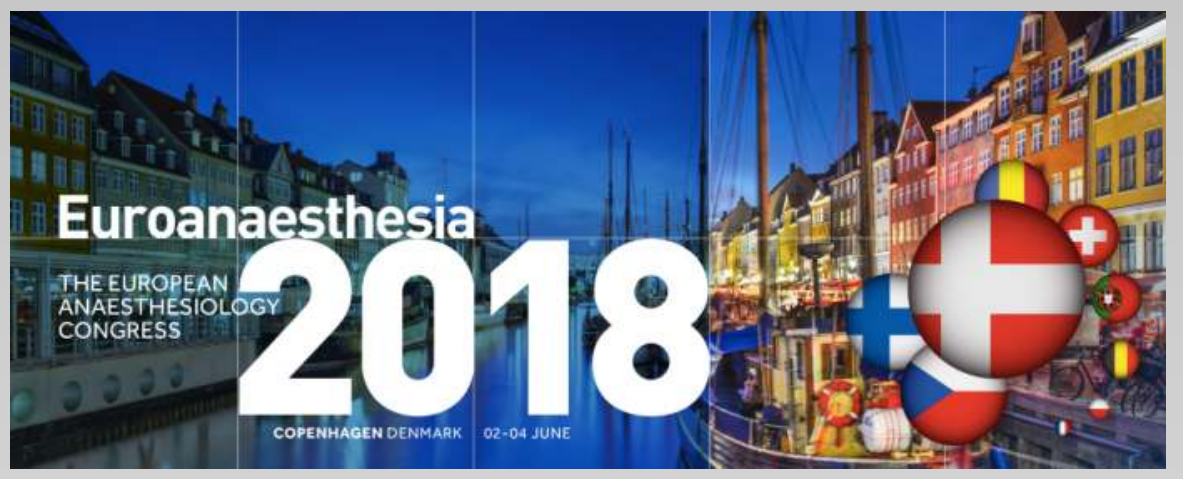

